\title{
Pilot-study of ridden walk on the circle - effects of progressive collection and lateral exercises
}

\author{
A. Egenvall ${ }^{1 *}$, H. Engström ${ }^{2}$ and A. Byström ${ }^{3}$ \\ 'Department of Clinical Sciences, Faculty of Veterinary Medicine and Animal Science, Swedish University of Agricultural Sciences, PO box \\ 7054, 75007 Uppsala, Sweden; ${ }^{2}$ Ekeskogs Riding Academy, Ekeskogs 906, 62375 Klintehamn, Sweden; ${ }^{3}$ Department of Anatomy, Physiology \\ and Biochemistry, Faculty of Veterinary Medicine and Animal Science, Swedish University of Agricultural Sciences, PO box 7054, 75007 \\ Uppsala, Sweden; agneta.egenvall@slu.se
}

Received: 10 May 2021 / Accepted: 5 August 2021

(c) 2021 Wageningen Academic Publishers

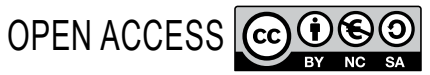

RESEARCH ARTICLE

\begin{abstract}
When collecting the horse, the rider influences stride length, forehand/hindquarters balance, and head-neck position. The study aim was to describe the vertical excursion of the withers and croup, and the sagittal cannon angles during collection and lateral exercises. Ten horses were ridden by five riders during 14 trials (1-5 per rider) on $10 \mathrm{~m}$ circles. Each trial included free walk, four degrees of increasing collection, and haunches-in and shoulderin. Inertial measurement units $(100 \mathrm{~Hz})$ were positioned on the withers, the first sacral vertebra (S1) and laterally on the cannons. Data for each exercise were stride-split. Range of motion (ROM), minima and maxima were studied in mixed models, controlling for stride duration. S1 vertical ROM ranged between 30-32 mm (highest degree of collection) and $51 \mathrm{~mm}$ (free walk), significantly smaller with increasing collection. S1 ROM during the inside hind limb step was smaller in haunches-in and shoulder-in compared to at the lowest degree of collection. Withers ROM ranged between $12 \mathrm{~mm}$ (lowest degree of collection) and 16-18 $\mathrm{mm}$ (highest degree of collection). Fore cannon protraction-retraction ROM ranged between $57^{\circ}$ (highest degree of collection) and $63^{\circ}$ (free walk). Hind cannon protraction-retraction ROM ranged between $47-50^{\circ}$ (highest degree of collection) and $51-56^{\circ}$ (free walk). All limbs had significantly smaller ROM at the highest degree of collection. Cannon ROMs were smaller for the outer limbs in haunches-in, and all limbs but the outer fore in shoulder-in, compared to the lowest degree of collection. Progressively decreasing ROM for fore- and hind limb cannons and S1 suggest that the riders achieved a shortening of the gait at higher degrees of collection. In shoulder-in and haunches-in, the diagonal oriented in the direction of motion showed decreased hind limb cannon ROM while forelimb cannon ROM was maintained, which could suggest increased shoulder freedom and collection of the targeted diagonal.
\end{abstract}

Keywords: equine, kinematics, horse-rider interaction, haunches-in, shoulder-in

\section{Introduction}

The walk is a relatively slow four-beat symmetrical gait. With four separated hoof placements, minimum and maximum vertical positions of the fore- and hindquarters become out of phase. Compared to trot, equine walk has less frequently been investigated scientifically. There have been studies on dressage characteristics of walk (Clayton, 1995; Rhodin et al., 2018; Weishaupt et al., 2006) and horse movement on a circle or during turning (Chateau et al., 2010; Egenvall et al., 2020a; Hobbs et al., 2011; Wakeling et $a l ., 2006)$. Protraction-retraction range of motion (ROM) was larger for outer compared to inner limbs when walking on a circle (Egenvall et al., 2020a).

Theoretically, horses can be ridden with almost no rider influence, apart from the rider's weight, in all gaits. The most common example of limited influence is free walk on long reins. Alternatively, the rider may seek to actively influence the horse's gait to a varying degree, ultimately aiming to control how each step is executed. When the rider strives to 'collect the horse', the main aspects that the 
rider aims to influence are the stride length, forward reach of the hind limbs, the forehand/hindquarters balance (to be less on the forehand), and the horse's head and neck position (in collection striving for the dorsum of the head to be vertical, with an arched neck with a relatively high poll). The hallmarks of collection described in equestrian texts are a decrease in stride length with retained energy of movement, increased flexion of the hind limb joints with lowering of the hindquarters, and increased protraction of the hind limbs (Branderup, 2001; De la Guérinière, 1729; Hess et al., 2012). These movement pattern changes are claimed to result in a shift of weight from the forelimbs to the hind limbs. However, comparing horses ridden at free walk and collected walk, only $1 \%$ of the body weight was transferred to the hindquarters (Weishaupt et al., 2006). Regarding kinematics, increased degree of collection in walk has been found to be associated with decreased stride length (Clayton, 1995). The stride frequency also decreased but to a lesser extent (Clayton, 1995). Increased flexion of the hock and stifle has been demonstrated (Rhodin et al., 2018). Equestrian authors have suggested that during basic schooling, collected walk should be avoided and the horse should mainly be worked in a low head-neck position, either with light rein contact or on loose reins, because constraining the walk may lead to problems, e.g. irregular walk (Hess et al., 2012). Collected walk can thus be considered a relatively difficult exercise for horses and riders.

During flatwork or dressage training horses are commonly ridden with lateral bending (Eisersiö et al., 2015). The slightest degree is having just a little bend to the left or right at the horse's poll (in German 'stellung'); for example, riding along the perimeter of the arena horses will most often be asked for 'stellung' to the inside of the arena. A higher degree of lateral bending is used when riding on circles or performing lateral exercises, e.g. shoulder-in or haunchesin. In lateral exercises the horse is ridden on three (or four) tracks relative to the direction of motion, and the rider asks for one of the hind limbs to step more in under the horse's body (FEI, 2020), i.e. collecting one diagonal at a time. For example, in a left shoulder-in on three tracks the horse is bent to the left and the left hind limb should follow the track of the right forelimb; engagement of the left hind limb is a main focus of the exercise. Rider's leg forces and saddle pressure have been measured during lateral exercises at the trot (De Cocq et al., 2010), to our knowledge the only study addressing lateral exercises.

The intention behind the current set-up was to study the biomechanics of various exercises in a realistic, yet reproducible, dressage training context. The aim of this pilot study was to examine vertical excursion of the withers and the croup, and sagittal cannon angles, during increasing degrees of collection and during lateral exercises (haunches-in and shoulder-in) in horses ridden in walk on the circle. It was hypothesised that there would be a doseresponse relationship between the degree of collection and both vertical midline and cannon ROM. It was further hypothesised that lateral exercises would show features similar to collection.

\section{Materials and methods}

\section{Horses and their equipment}

The experiment took place at one training facility, using horses that had been stabled there for at least 2 months. Data on breed, gender, age, withers height, and time with the owner were recorded for each horse (Table 1). All horses were trained in classical dressage since several years and were experienced in performing the exercises included in the study. The rider/trainer of the horse was asked a set of questions to appreciate sidedness during training and riding for each horse (Supplementary Table S1). The horses were deemed sound by a veterinarian (AE) who before the experiment watched the horses work for several sessions in walk and trot in the arena where the experiment took place. All the horses were deemed fit to perform the study protocol. The horses were equipped with their custom saddle (one horse was ridden bare-back) and head gear (Table 1). A cavesson was used for lunging and was kept on during riding; one horse was ridden bitless on the cavesson. According to Swedish law this study did not need specific ethical approval, neither for the participation of the riders nor the horses. Riders and horse owners provided written informed consent.

\section{Riders and their equipment}

One trainer (HE) and four of her students participated. The riders were female, aged 18, 20, 21, 49 and 57 years, with weights and heights ranging from $61-66 \mathrm{~kg}$ and $158-173 \mathrm{~cm}$. All students had been training regularly with the trainer since at least 4 years. All riders considered themselves righthanded. All riders were accustomed to their mounts but varying from that they rode their own horses to that they had ridden the horse 5 times previously. Riders wore safety helmets and carried a dressage whip (rarely used during the experiment), while spurs were not used. Some horses were ridden by several riders (Table 1), but there was no intention to cross all horses and riders.

\section{Design}

The whole experiment comprised a sequence of exercises, which allowed the horses some warm-up in free walk without a rider and continued with progressive collection under rider. The horses were first measured walking straight in an alley on concrete, with equipment but without rider. The rest of the exercises were performed on a $10 \mathrm{~m}$ diameter circle that was prepared by drawing a perimeter trace on a soft 
Table 1. Details on the 10 horses in the study.,2

\begin{tabular}{|c|c|c|c|c|c|c|c|c|}
\hline $\begin{array}{l}\text { Horse } \\
\text { no. }\end{array}$ & Breed & Gender & Age (yrs) & $\begin{array}{l}\text { Height at } \\
\text { withers }(\mathrm{cm})\end{array}$ & $\begin{array}{l}\text { Duration with } \\
\text { owner (yrs) }\end{array}$ & Saddle & Bridle & Hollow side \\
\hline 1 & Russian crossbred/PRE 3 & Gelding & 17 & 158 & 3 & Acad saddle ${ }^{4}$ & Kimberwick, straight bar & Left \\
\hline 2 & Lusitano & Gelding & 11 & 150 & 2 & Acad saddle & Snaffle, straight bar, D-rings & Right \\
\hline 3 & Knabstrupper & Mare & 11 & 155 & 7 & Acad saddle & Baucher & Left \\
\hline 4 & PRE & Mare & 13 & 158 & 4 & Acad saddle & Baucher & Left \\
\hline 5 & Lusitano & Mare & 16 & 154 & 10 & Acad saddle & Curb bit & Neither \\
\hline 6 & Newforest & Gelding & 15 & 138 & 4 & Bareback & Bitless, cavesson & Left \\
\hline 7 & PRE & Mare & 17 & 158 & 13 & Acad saddle & Kimberwick, straight bar & Left \\
\hline 8 & Lusitano & Mare & 7 & 155 & 1 & Acad saddle & Snaffle & Neither \\
\hline 9 & PRE & Stallion & 11 & 153 & 10 & Acad saddle & Snaffle with eggbutt rings & Right \\
\hline 10 & PRE/Frederiksborg horse & Mare & 11 & 158 & 11 & Acad saddle & Kimberwick, straight bar & Right \\
\hline
\end{tabular}

\footnotetext{
${ }^{1}$ Rider 1 rode horse 1, 2, 5, 7 and 9, rider 2 horse 3 and 4, rider 3 horse 1, 2, 5 and 10, rider 4 horse 6 , and rider 5 horse 6 and 8 .

${ }^{2}$ Hollow side is evaluated from Supplementary Table S1.

${ }^{3} \mathrm{PRE}=$ pura raza Española.

${ }^{4}$ Acad saddle $=$ academic leather tree saddle.
}

sand-fibre surface in an indoor arena. The horses were first lunged in freely moving walk without rider a few circles to the left and to the right (initial lunging direction, left/right, was alternated between measurement days). Directly after this the rider mounted. Beginning in the opposite direction compared to lunging, the rider performed the following walk exercises: free walk on long reins ('free walk'); gently framing the horse between the seat, upper legs and hand, but not using rein or seat aids actively ('neutral seat'); adding a light half-halt during inside hind limb stance asking the horse for some collection ('neutral seat with one half-halt'); performing a light half-halt during each hind limb stance, asking for more collection ('neutral seat with double half-halts'); and finally at full collection where the riders strived to maintain their pelvis caudally rotated, limiting pelvic pitch through the whole stride, asking the horse for as much collection as the horse was able to perform ('full seat'). Neutral seat was then adopted again and haunches-in and shoulder-in were performed. The riders were allowed to alternate between haunches-in and shoulder-in until a successful attempt was recorded for each of these. This was followed by some strides in neutral seat ('neutral seat aft') and about one circle in free walk ('free walk aft'). The ridden exercises were then repeated in the other direction. Only data from the ridden exercises were used in the current analysis. The riders, and the trainer, evaluated the exercises out loud during the ride, to aid in later extraction of the best performed part of each exercise based on the video recordings.

\section{Equipment}

Inertial measurement unit (IMU) sensors ( $\mathrm{x}$-io Technologies Limited, Bristol, UK) were positioned on the withers, the croup and laterally on the cannons of all four limbs (Figure 1); for midline sensors linear acceleration was positive upwards, and for cannon sensors pitch was positive for clockwise rotation as seen from the horse's left side, i.e. equivalent to protraction (other IMU-recorded data not used in the study). IMU size was $56 \times 39 \times 18 \mathrm{~mm}$, weight $46 \mathrm{~g}$ and with 16-bit resolution. The sampling rate was set to $100 \mathrm{~Hz}$. The IMU sensors were synchronised using dedicated software (https://x-io.co.uk/ngimu/). The experiments were videorecorded (Sony FDR-AX53, Tokyo, Japan) at $25 \mathrm{~Hz}$. When recording trials on the circle the camera was positioned in the middle of the circle. To synchronise the video and the measurements, the IMU sensors were tapped (all positioned on a chair) in front of the camera just after starting and before turning the sensors off.

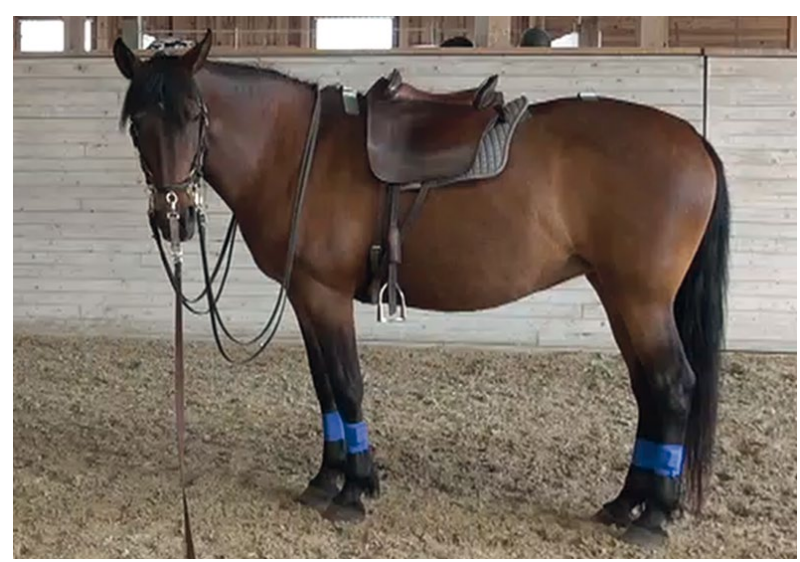

Figure 1. Study horse with equipment and tack. The withers sensor is placed in front of the saddle, the S1 sensor on the croup and cannons sensors are placed laterally. (The saddle cloth is placed to the rear to avoid interference with the withers sensor.) 


\section{Data analysis}

The videos were scrutinised. The seconds with the "bestexecuted' sequences were recorded for each exercise and direction by author AE. When selection was difficult this was resolved in consensus with author AB. Data for the selected sequences were split in steps and strides based on maximum protraction of the hind limbs and were visually inspected before inclusion. Step and stride normalised (to 100 points) data curves were plotted for visualisation. For the vertical position of the withers and S1, ROM was calculated from step-normalised data. For cannon sagittal angles, ROM and values for and timing of maximum protraction and retraction, were calculated from stridenormalised data. For timing of forelimb cannon maximum retraction, timing values $>90 \%$ were subtracted by 100 . This was done in order for all timings to be expressed relative to the beginning of the stride.

\section{Statistics}

Descriptive and analytical statistics were made using SAS (SAS Institute Inc., Cary, NC, USA). S1 and withers step data and cannons stride data were analysed in mixed models (proc MIXED). Stride duration (in s) was entered as a fixed linear effect in all models, after having verified that a linear fit was a reasonable assumption. The general random parameter structure consisted of rider, horse, rider-horse combination and specific exercise (e.g. free walk in left direction) within rider-horse combination. The SAS-option pdiff was used for calculating least square means and for follow-up testing of selected pairwise comparisons. The $P$-value limit for statistical significance was set to $<0.05$. $P$-values were not adjusted for multiple comparisons.

\section{The following two groups of models were created:}

1. Models were constructed from step-normalised data, with ROM for the vertical displacement of the withers and of S1 as dependent variables. Each observation was labelled as an inside or outside hind limb step. Fixed categorical effects were step (inside or outside), exercise (ignoring direction) and the two-way interaction between step and exercise. Comparisons were made between (a) progressively increasing degree of collection, (b) neutral seat and each of the collected exercises, (c) neutral seat and lateral exercises, and (d) free walk in the beginning versus after exercise. Comparisons were made within step (inside/outside).

2. Models were constructed from stride-normalised data, with cannon ROM, and minima and maxima and their timing, as dependent variables. Fixed categorical effects were limb (inner fore, outer fore, inner hind, outer hind) and exercise, including the two-way interaction between limb and exercise. In this analysis, exercise sequences with data for only stride were excluded. Principally the same pairwise comparisons were made as for model 1.

3. A model with stride duration as outcome was created, with the same general random effects as above. Fixed effects were exercise and hind limb cannon ROM (the left limb value was used), the latter was graphically checked for linearity vs stride duration.

4. Subjective laterality was tested upon the withers, S1 and cannon ROM models as an interaction with inside/ outside step (withers and S1 models) or limb (cannon model). Hollow side (left/right) was tested in two variants (in separate models). The horses denoted as 'neither' were either categorised as left (one model) or right-lateralised (one model, Table 1), because some horses could not be clearly evaluated as left or rightlateralised.

To achieve normality of residuals the following steps were taken. If variable means and medians were close, standard deviations relatively small and skewness and kurtosis close to zero, variables were analysed in untransformed formats. If this was not the case variables were Box Cox transformed and the best practical transformation for each variable was adopted. Residual plotting was employed in the last step to evaluate whether residuals were normally distributed (not ideal for the cannon timing variables).

\section{Results}

From placing the sensors until their removal each trial took 35-50 min. The number of strides and trials per exercise are shown in Supplementary Table S2 (e.g. only 12 of 14 trials had data on 'free walk aft'). One horse (in one trial) had synchronisation failure for S1 data, hence S1 analyses included 9 horses (13 trials). For 21 exercise sequences only one stride was retained for analysis, nine of these were for lateral exercises. In general, there were somewhat more strides included for free walk compared to the other exercises (Supplementary Table S2). Stride duration increased progressively with collection (Table 2).

Figure 2 and Supplementary Figure S1 show examples of time-normalised traces of withers and S1 vertical displacement and Supplementary Figure S2 shows cannon pitch (upper graphs outer hind and inner fore, lower graphs inner hind and outer fore), all from the same horse. It is evident that the withers traces, over the course of the exercises, were more irregular than the other parameters. The same was observed for all the horses in the study.

Supplementary Results S1 contains model output, data and SAS-code for all models. All models except withers and S1 ROM were analysed untransformed. 
Table 2. Least square means estimates (Est) and standard errors (SE) reported by exercise for the model with stride duration (s) as outcome ( $n=1,714$ strides, from 10 horses during 14 trials).

\begin{tabular}{|c|c|c|c|}
\hline Exercise & Est & SE & Selected comparisons ${ }^{1}$ \\
\hline Free walk & 1.299 & 0.050 & \\
\hline Neutral seat (NS) & 1.357 & 0.050 & \\
\hline NS one half-halt & 1.417 & 0.050 & \\
\hline NS double half-halt & 1.462 & 0.050 & \\
\hline Full seat & 1.578 & 0.050 & \\
\hline Haunches-in & 1.410 & 0.050 & \\
\hline Shoulder-in & 1.393 & 0.050 & \\
\hline NS after exercise & 1.376 & 0.050 & \\
\hline Free walk after exercise & 1.313 & 0.050 & \\
\hline
\end{tabular}

${ }^{1}$ Grey comparisons are non-significant $(P>0.05)$, black $0.01<P<0.05$ and magenta $P<0.01$.

\section{Withers ROM}

The exercise $\times$ step interaction was significant at $P<0.0001$ and stride duration was significant at $P=0.001$ (least square means for the different exercises were calculated at grand mean stride duration). Withers ROM increased with increasing stride duration (positive coefficient 0.26 (standard error $(\mathrm{SE})=0.08$ ) on the logarithm-transformed scale). Withers ROM ranged between $12 \mathrm{~mm}$ (low degree of collection) and $18 \mathrm{~mm}$ (outside hind limb step in full seat, Table 3). It should be noted that the inside hind limb step, the period from inner hind limb maximum protraction to outer hind limb maximum protraction, includes first a withers maximum related to midstance of the outer forelimb and then a withers minimum at inner forelimb early stance, and vice versa for the outside hind limb step.
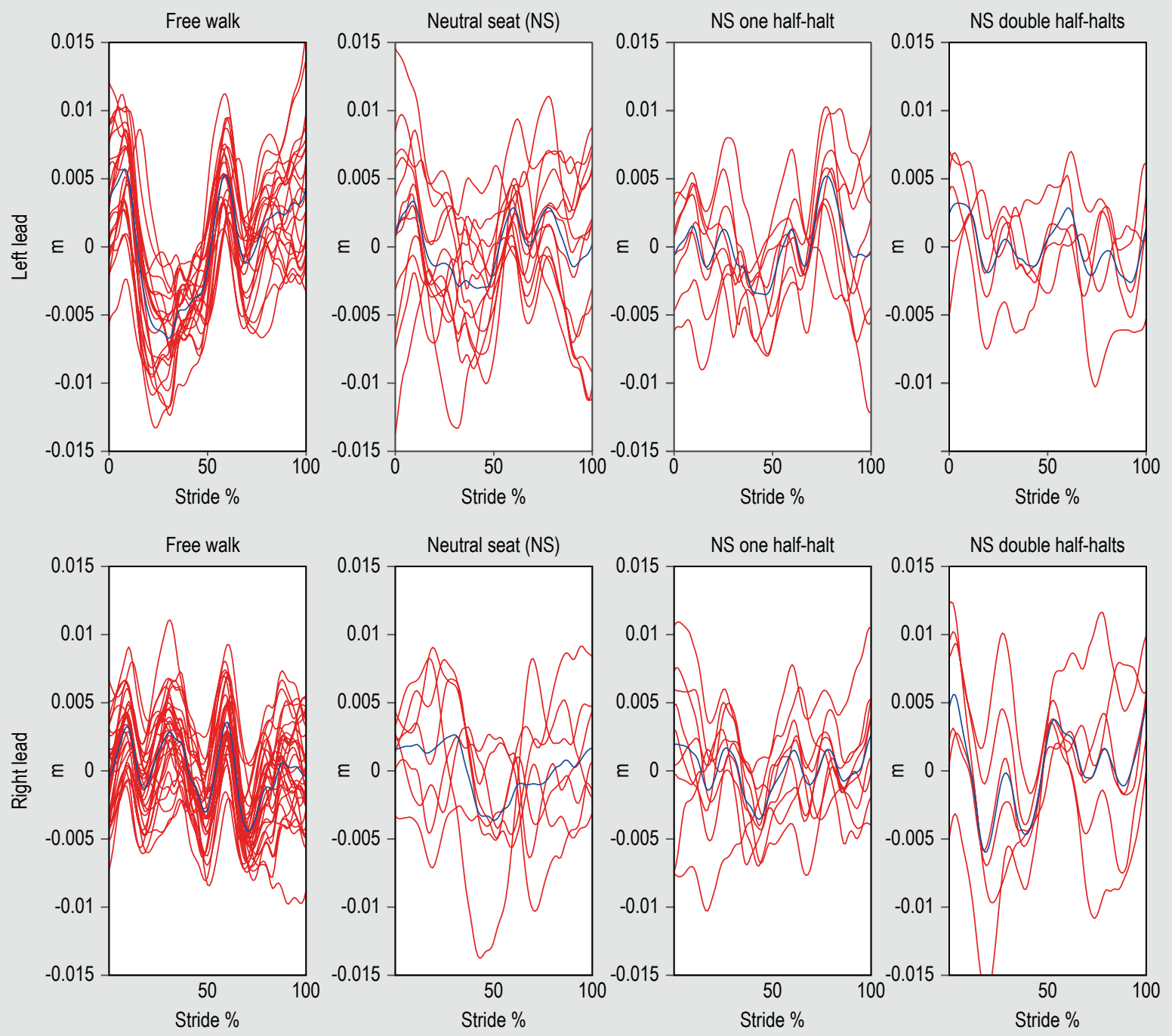

Figure 2. Time-normalised stride data (single strides in red, mean of all strides in blue) for the withers vertical displacement by exercise, in left (upper row) and right (bottom row) directions on the circle (horse 2, trial 2). $0-100 \%$ of the stride (x-scale) is relative to inner hind limb maximum protraction. 

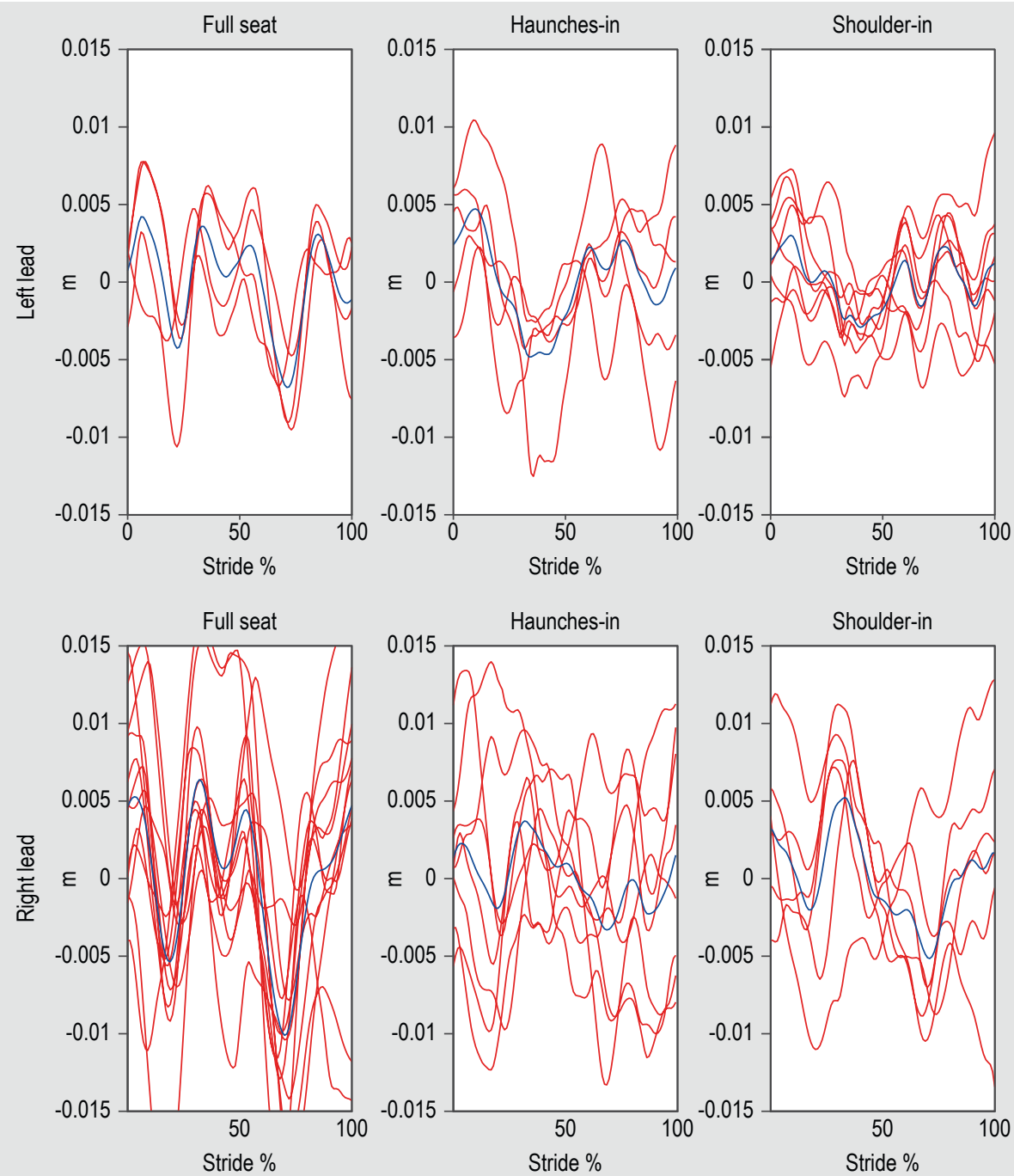

Figure 2. Continued. Time-normalised stride data (single strides in red, mean of all strides in blue) for the withers vertical displacement by exercise, in left (upper row) and right (bottom row) directions on the circle (horse 2, trial 2 ). $0-100 \%$ of the stride $(x$-scale) is relative to inner hind limb maximum protraction.

Comparing increasing degrees of collection ( $\mathrm{a}$ and $\mathrm{b}$ comparisons), the highest withers ROM estimate was found for the highest degree of collection. Comparing lateral exercises to neutral seat, withers ROM was higher for the inside step in haunches-in and both steps in shoulder-in. Comparing free walk before and after the other exercises, withers ROM was increased after.

\section{S1 ROM}

For S1 ROM the exercise $\times$ step interaction was significant at $P=0.02$ and stride duration was significant at $P<0.0001$. $S 1 \mathrm{ROM}$ decreased with increasing stride duration (negative coefficient, $-0.073(\mathrm{SE}=0.005)$ on the squareroot transformed scale).

S1 ROM ranged between $30 \mathrm{~mm}$ (outside step in full seat) and $51 \mathrm{~mm}$ ('free walk aft', Table 4). Several significant comparisons indicated that increased degree of collection was associated with smaller S1 ROM (for both inside and outside steps). Inside step S1 ROM in haunches-in, as well as inside step S1 ROM in shoulder-in, were smaller compared to neutral-seat (c) haunches-in. Comparing free walk before and after (d), 'free walk aft' had larger S1 ROM compared to free walk at the beginning, for both inside and outside steps.

\section{Cannon ROM, protraction and retraction}

For cannon $\mathrm{ROM}$ the exercise $\times$ limb interaction was significant at $P<0.0001$ and stride duration was significant at $P<0.0001$. The stride duration estimate was -6.53 (SE $=0.65)$, suggesting that cannon ROM decreased with increasing stride duration. For maximum protraction, the exercise $\times$ limb interaction was significant at $P=0.0002$ and stride duration was non-significant at $P=0.16$. For 
Table 3. Results and comparisons for the withers range of motion model. ${ }^{1}$

\begin{tabular}{|c|c|c|c|c|c|c|c|c|}
\hline Exercise & Step & Est & SE & BT & a. Increasing collection & b. Neutral to collection & c. Neutral to lateral & d. Before and after \\
\hline \multirow[t]{2}{*}{ Free walk } & inside & -4.41 & 0.09 & 12.1 & & & & \\
\hline & outside & -4.46 & 0.09 & 11.6 & & & & \\
\hline \multirow[t]{2}{*}{ Neutral seat (NS) } & inside & -4.36 & 0.09 & 12.8 & & & & \\
\hline & outside & -4.45 & 0.09 & 11.7 & & & & \\
\hline \multirow[t]{2}{*}{ NS one half-halt } & inside & -4.32 & 0.09 & 13.3 & & & & \\
\hline & outside & -4.37 & 0.09 & 12.6 & & & & \\
\hline \multirow[t]{2}{*}{ NS double half-halt } & inside & -4.19 & 0.09 & 15.1 & & & & \\
\hline & outside & -4.29 & 0.09 & 13.7 & & & & \\
\hline \multirow[t]{2}{*}{ Full seat } & inside & -4.14 & 0.10 & 15.9 & & & & \\
\hline & outside & -4.03 & 0.10 & 17.7 & & & & \\
\hline \multirow[t]{2}{*}{ Haunches-in } & inside & -4.19 & 0.09 & 15.2 & & & & \\
\hline & outside & -4.28 & 0.09 & 13.9 & & & & \\
\hline \multirow[t]{2}{*}{ Shoulder-in } & inside & -4.23 & 0.09 & 14.5 & & & & \\
\hline & outside & -4.23 & 0.09 & 14.6 & & & & \\
\hline \multirow{2}{*}{$\begin{array}{l}\text { Free walk after } \\
\text { exercise }\end{array}$} & inside & -4.31 & 0.09 & 13.5 & & & & \\
\hline & outside & -4.28 & 0.09 & 13.8 & & & & \\
\hline
\end{tabular}

Table 4. Results and comparisons for the S1 range of motion model.1

\begin{tabular}{|c|c|c|c|c|c|c|c|c|}
\hline Exercise & Step & Est & SE & BT & a. Increasing collection & b. Neutral to collection & c. Neutral to lateral & d. Before and after \\
\hline \multirow[t]{2}{*}{ Free walk } & inside & 0.217 & 0.004 & 47.0 & & & & \\
\hline & outside & 0.215 & 0.004 & 46.1 & & & & \\
\hline \multirow{2}{*}{$\begin{array}{l}\text { Neutral seat } \\
\text { (NS) }\end{array}$} & inside & 0.202 & 0.004 & 40.8 & & & & \\
\hline & outside & 0.203 & 0.004 & 41.2 & & & & \\
\hline \multirow[t]{2}{*}{ NS one half-halt } & inside & 0.192 & 0.005 & 36.7 & & & & \\
\hline & outside & 0.191 & 0.005 & 36.6 & & & & \\
\hline \multirow{2}{*}{$\begin{array}{c}\text { NS double } \\
\text { half-halt }\end{array}$} & inside & 0.182 & 0.005 & 33.1 & & & & \\
\hline & outside & 0.184 & 0.005 & 33.9 & & & & \\
\hline \multirow[t]{2}{*}{ Full seat } & inside & 0.179 & 0.005 & 31.9 & & & & \\
\hline & outside & 0.174 & 0.005 & 30.1 & & & & \\
\hline \multirow[t]{2}{*}{ Haunches-in } & inside & 0.188 & 0.005 & 35.2 & & & & \\
\hline & outside & 0.188 & 0.005 & 35.4 & & & & \\
\hline \multirow[t]{2}{*}{ Shoulder-in } & inside & 0.197 & 0.005 & 38.8 & & & & \\
\hline & outside & 0.195 & 0.005 & 38.1 & & & & \\
\hline \multirow{2}{*}{$\begin{array}{l}\text { Free walk after } \\
\text { exercise }\end{array}$} & inside & 0.226 & 0.005 & 50.9 & & & & \\
\hline & outside & 0.225 & 0.005 & 50.8 & & & & \\
\hline
\end{tabular}

${ }^{1}$ Least square means estimates (Est) with standard errors (SE) on the square-root transformed scale (original scale in $\mathrm{m}$ ), back-transformed estimates (BT in $\mathrm{mm}$ ) and evaluated pairwise comparisons ( $n=3,471$ steps, from 9 horses in 13 trials). Grey comparisons are non-significant $(P \geq 0.05)$, black $(0.01<P<0.05)$ and magenta $(P \leq 0.01)$. 
maximum retraction, the exercise $\times$ limb interaction was significant at $P<0.0001$ and stride duration was significant at $P<0.0001$. The stride duration estimate was $5.56(\mathrm{SE}=$ 0.66 ) suggesting that a longer stride duration was associated with a larger (less negative) maximum retraction angle, i.e. decreased cannon retraction.

Forelimb cannon pitch ROM ranged between $57^{\circ}$ (both forelimbs in full seat) and $63^{\circ}$ (both forelimbs in 'free walk aft', Table 5). Hind limb cannon pitch ROM ranged between $47^{\circ}$ (inner hind in full seat) and $56^{\circ}$ (outer hind in free walk both before and after exercises). Forelimb maximum protraction varied between $16^{\circ}$ (outer fore in full seat) and $21^{\circ}$ (inner fore in 'free walk aft'), and hind limb maximum protraction between $34^{\circ}$ (inner hind 'neutral seat with double half-halts' and full seat) and $39^{\circ}$ (outer hind in both free walk categories) (Table 6). Forelimb maximum retraction varied between $-40^{\circ}$ (inner fore in 'neutral seat with double half-halts' and full seat) and $-43^{\circ}$ (outer fore in 'free walk aft'), and hind limb maximum retraction between $-13^{\circ}$ (inner hind full seat) and $-17^{\circ}$ (outer hind in both free walk categories) (Table 7). A number of significant comparisons indicated that cannon ROM decreased with increasing collection. Correspondingly, several significant differences (involving all four limbs) between higher degrees of collection and neutral seat indicated that maximum protraction was the smallest in higher degrees of collection (Table 6). Maximum retraction (Table 7) of both hind limbs was reduced in full seat compared to neutral seat.

Table 5. Results and comparisons for the cannon range of motion model.1

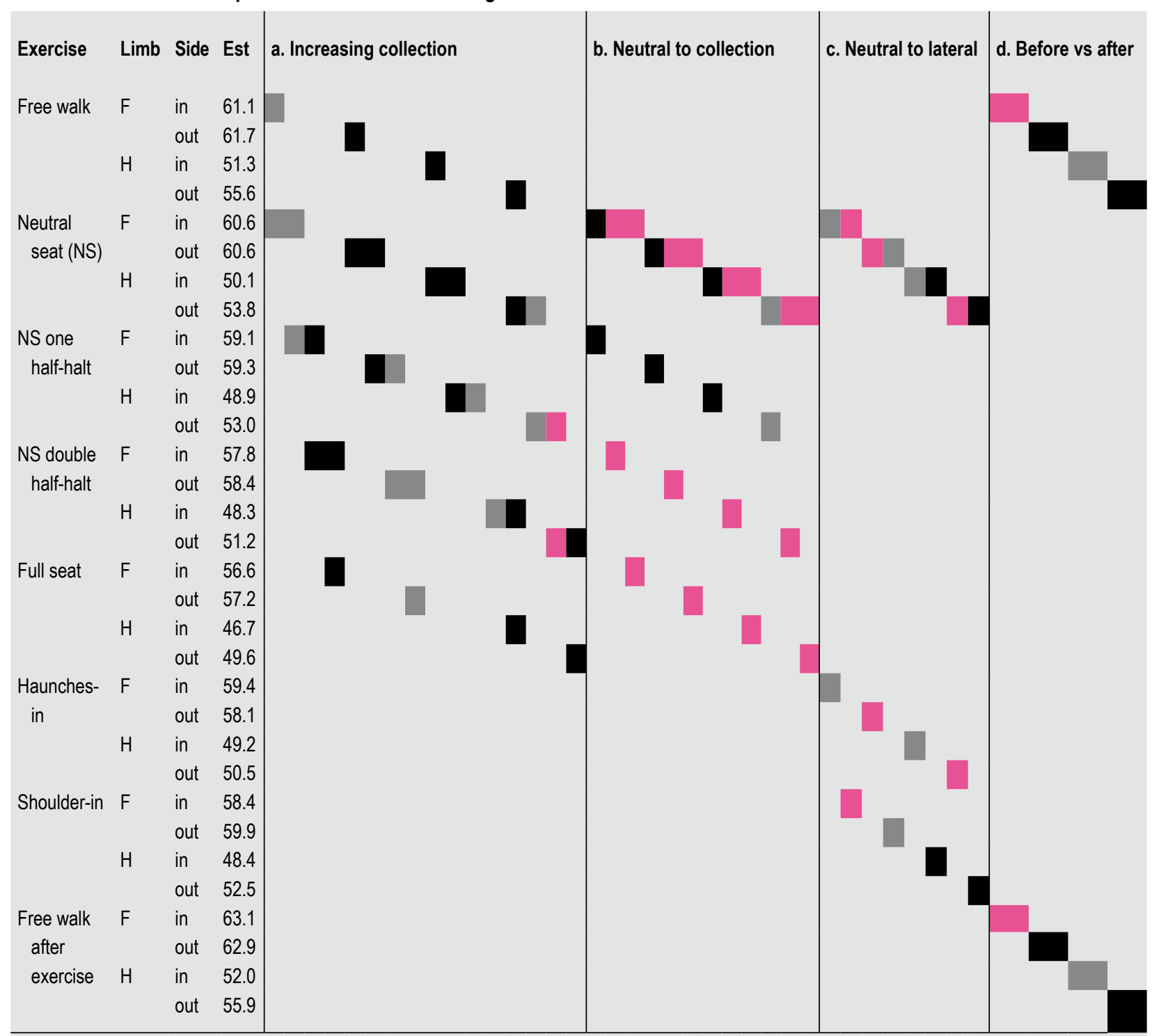

${ }^{1}$ Least square means estimates (Est) in degrees and evaluated pairwise comparisons ( $n=6,772$ strides, from 10 horses in 14 trials). The standard error is 1.1 degrees for all estimates. Grey comparisons are non-significant $(P \geq 0.05)$, black $(0.01<P<0.05)$ and magenta $(P \leq 0.01)$. 
Table 6. Results and comparisons for the maximum cannon protraction motion model. ${ }^{1}$

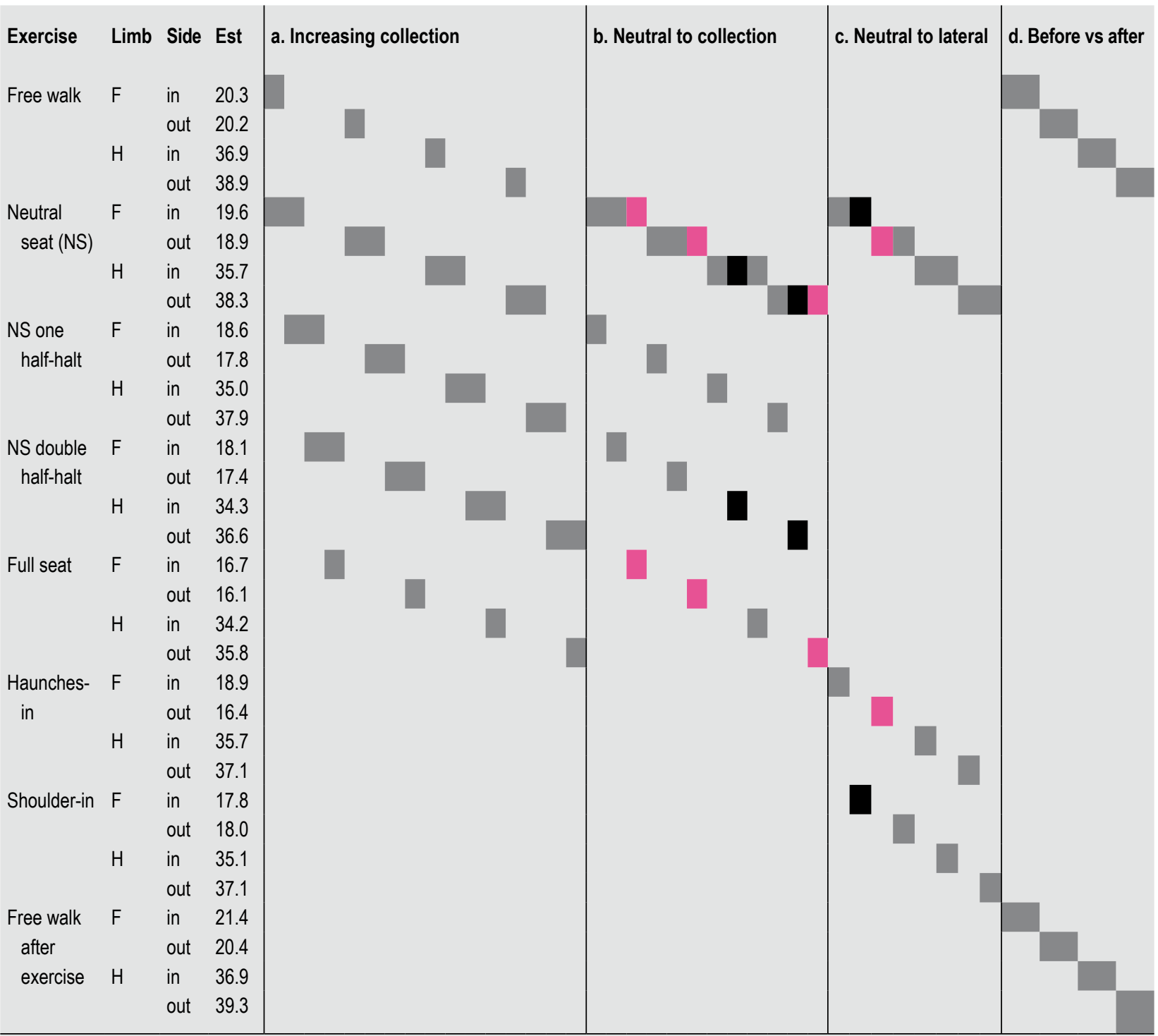

${ }^{1}$ Least square means estimates (Est) in degrees and evaluated pairwise comparisons ( $n=6,772$ strides, from 10 horses in 14 trials). The standard error is 1.1 degrees for all estimates. Grey comparisons are non-significant $(P \geq 0.05)$, black $(0.01<P<0.05)$ and magenta $(P \leq 0.01)$.

Comparing cannon ROMs (Table 5) in lateral exercises and in neutral seat (c), ROMs were generally smaller for the lateral exercises. Maximum protraction became smaller for the inner fore in shoulder-in and the outer fore in haunchesin (Table 6). Maximum retraction of the outer hind became smaller in haunches-in (Table 7). Comparing free walk to 'free walk aft' cannon ROMs in 'free walk aft' were slightly larger for three of four limbs (Table 5).

\section{Timing of cannon maximum protraction and retraction}

For timing of cannon maximum protraction, the exercise $\times$ limb interaction was significant at $P<0.0001$ and stride duration was non-significant at $P=0.22$. Time of maximum protraction varied between $28 \%$ of the stride (free walk) and $31 \%$ of the stride (full seat, shoulder-in) for the inner forelimb and between $76 \%$ (full seat) and $80 \%$ (neutral seat) for the outer forelimb. Maximum protraction occurred at $\sim 0 \%$ for the inner hind limb (stride start defined from this event), and varied between $47 \%$ (free walk and shoulderin) and 49\% (full seat) for the outer hind limb (Table 8). Collection influenced the outer forelimb only, for which maximum protraction occurred earlier with increased collection. Comparing neutral seat and lateral exercises, outer forelimb maximum protraction occurred earlier in shoulder-in. Inner forelimb maximum protraction occurred later in 'free walk aft' than in free walk at the beginning. 
Table 7. Results and comparisons for the maximum cannon retraction model. ${ }^{1}$

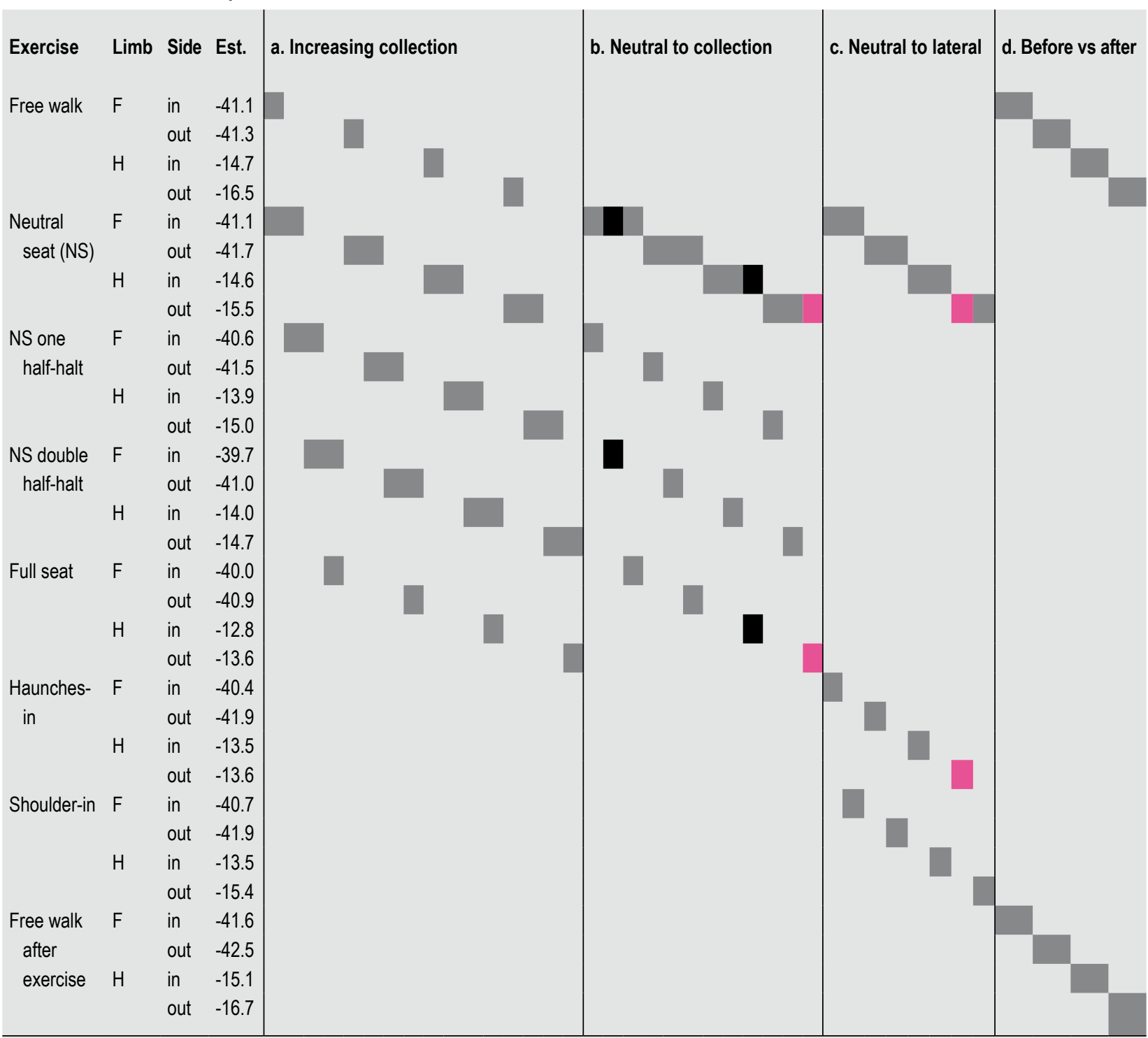

${ }^{1}$ Least square means estimates in degrees and evaluated pairwise comparisons ( $n=6,772$ strides, from 10 horses in 14 trials). The standard error is 1.1 degrees for all estimates. Grey comparisons are non-significant $(P \geq 0.05)$, black $(0.01<P<0.05)$ and magenta $(P \leq 0.01)$.

For timing of cannon maximum retraction, the exercise $\times$ limb interaction was significant at $P<0.0001$ and stride duration was significant at $P<0.0001$. The estimate for stride duration was $8.60(\mathrm{SE}=1.07)$. Time of maximum retraction varied between $4 \%$ (free walk) and 9\% (full seat, haunches-in and shoulder-in) for the inner forelimb, and between $55 \%$ ('free-walk aft') and $61 \%$ (full seat) for the outer forelimb. Time of maximum retraction varied between $66 \%$ (free walk) and 69\% ('neutral seat with double half-halts' and haunches-in) for the inner hind limb, and between 15\% ('free walk aft') and 19\% (full seat) for the outer hind limb (Table 9). Both forelimbs and the outer hind limb reached maximum retraction later at high degree of collection compared to neutral seat. Maximum retraction of the inner fore occurred later in haunches-in and shoulder-in compared to in neutral seat. Maximum retraction of the inner fore occurred later in 'free-walk aft' compared to free walk at the beginning.

\section{Laterality}

Hollow side and its interaction with inner/outer step or limb were tested upon the full ROM models, the interaction being significant for withers $\operatorname{ROM}(P=0.01$, significant using one of two variant variables) and $\mathrm{S} 1$ and cannon $\mathrm{ROM}(P<0.0001)$. However, relevant comparisons, e.g. the hollow side as inner side vs the stiffer side as inner side, were all associated with large $P$-values (Supplementary Results S1). 
Table 8. Results and comparisons for timing of maximum cannon protraction model. ${ }^{1}$

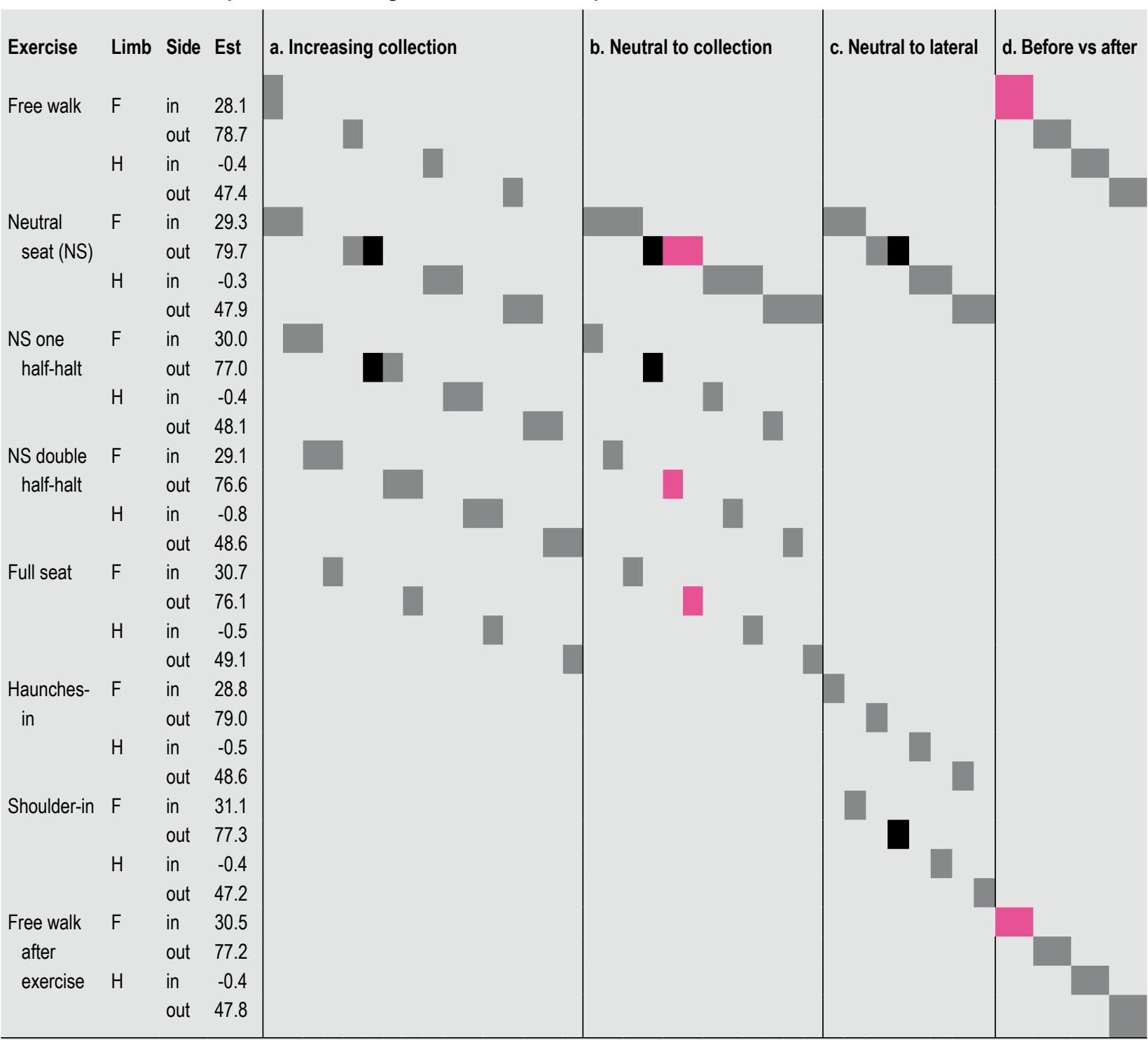

${ }^{1}$ Least square means estimates (Est) in percent of the stride and evaluated pairwise comparisons ( $n=6,772$ strides, from 10 horses in 14 trials). The standard error is $0.8 \%$ for all estimates. Grey comparisons are non-significant $(P \geq 0.05)$, black $(0.01<P<0.05)$ and magenta $(P \leq 0.01)$.

\section{Discussion}

In this exploratory study, progressively increasing degree of collection, and lateral exercises, were studied in walk on the circle. Working the horse on a circle is common in horse training, and horses are frequently ridden with some degree of lateral bending (Eisersiö et al., 2015). Considering that the walk is a symmetrical gait, maximum cannon protraction of the outer hind limb can be expected to occur at $50 \%$ of the stride relative to maximum protraction of the inner hind. However, maximum outer hind protraction was found to occur between 47 to $49 \%$ depending on exercise, reflecting a circle-induced asymmetry (Egenvall et al., 2020a). Maximum forelimb protraction occurred in-between these events, at 28 to $31 \%$ for the inner, and at 76 to $80 \%$ for the outer. The asymmetry in limb timing on the circle is likely related to asymmetry in limb protractionretraction. Protraction-retraction ROM for outer fore- and hind limbs, and maximum protraction of the outer hind limb, were found to be larger compared to the respective inner limb (Egenvall et al., 2020a), and the outside pair of limbs were also found to have longer stride length (Hobbs et al., 2011), in horses walking in $10 \mathrm{~m}$ circles on soft surface. In the current study, the effects of collection were similar for the inner and outer limbs.

Cannon protraction-retraction ROM generally decreased significantly with increasing degree of collection, for both 
Table 9. Results and comparisons for the timing of maximum cannon retraction model. ${ }^{1}$

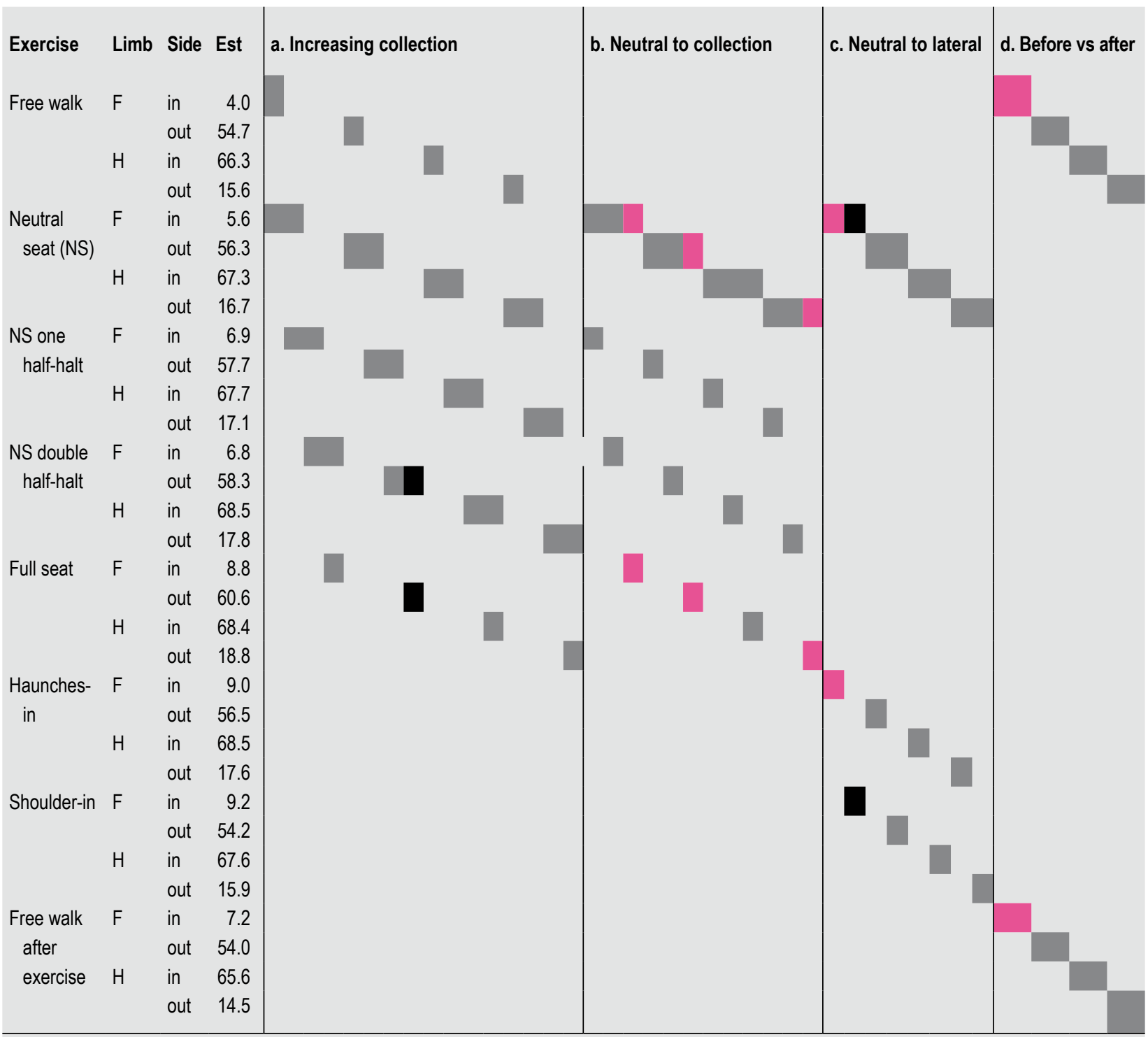

${ }^{1}$ Least square means estimates (Est) in percent of the stride and evaluated pairwise comparisons ( $n=6,772$ strides, from 10 horses in 14 trials). The standard error is $0.9-1.0 \%$ for all estimates. Grey comparisons are non-significant $(P \geq 0.05)$, black $(0.01<P<0.05)$ and magenta $(P \leq 0.01)$.

fore- and hind limbs, and both inner and outer limbs. In earlier research, forelimb cannon ROM decreased with 6\% and hind limb cannon ROM with $5 \%$ going from medium to collected walk (Clayton, 1995). Our figures going from neutral seat to the highest degree of collection (full seat) were $3-4 \%$. Along with decreased cannon ROM, maximum protraction became smaller with increasing collection for both inner and outer fore- and hind limbs. The latter has also been found in previous studies of collection in walk on the straight (Clayton, 1995; Rhodin et al., 2018). For the inner and outer hind limbs, maximum retraction was also decreased at the highest degree of collection, again in line with previous studies comparing collected vs less collected walk (Clayton, 1995; Rhodin et al., 2018). In summary, the horses in the current study showed similar features in collection compared to findings in previous studies. This confirms that collection has distinct kinematic features, and these appear to be comparably consistent between circle and straight line.

Croup vertical ROM became progressively smaller as the horses in the current study became more collected, concurrent with a decrease in hind limb cannon ROM. This association can be expected from the geometry of an inverse pendulum model, hence it is not unique to collection per se. 'To put the horse on the haunches', is an early term for collection (Newcastle, 1658; Xenophon, 350 BC), which would imply that the croup should be lowered, possibly 
concurrent with a smaller ROM. Measurements of the actual height of the croup is not possible with IMU-technique, but previous studies found no significant decrease in croup height in collection, neither in walk nor in trot (Rhodin et al., 2009, 2018). However, collection can feature increased angulation of the pelvis (Rhodin et al., 2009, 2018), which lowers the base of the tail if croup height is constant. Other features of collection described in equestrian texts include a decrease in stride length with retained energy of movement (Branderup, 2001; De la Guérinière, 1729; Hess et al., 2012). It is further stated that the tempo should not decrease in collection (FEI, 2020), i.e. stride duration should not increase. Stride length, speed and stride duration are basic characteristics of a gait. They influence most kinematic variables, in addition to being interrelated. Collection entails a decrease in speed, making it challenging to study the effects of collection separate from those of speed. In the current study, stride duration did increase significantly with increasing collection, in line with a previous study (Clayton, 1995). Stride length and speed generally decrease with collection in walk while stride duration increases (Clayton, 1995). However, cannon protraction-retraction ROM was significantly reduced in collection despite correcting for stride duration in (all) the statistical models. Stride duration was used as an indicator for speed, since speed could not be measured with the IMUs. This finding would suggest that protraction-retraction ROM decreased more than can be expected from the decrease in stride duration alone. It could even be discussed if controlling for stride duration is preferable to controlling for speed, since a decrease in stride duration is not considered a genuine feature of collection. The collection we studied was performed during training, where exercises may be performed differently to at competition, regarding intensity and duration. Comparing our findings with the competition rules or the equestrian literature, it must also be noted that equestrian masters have formulated their biomechanical descriptions from sight, hearing and feel, and whether the equestrians meant the same (or different) things using one word (or another) in a specific situation is impossible to verify. Consequently, the features we and other researchers have measured may not be those that the equestrians looked at, and the question of agreement cannot be definitely answered.

In a haunches-in the rider asks the horse to place the outside hind limb closer to the midline, and in a shoulder-in it is instead the inside hind limb that should be placed closer to the midline (Hess et al., 2012; Steinbrecht, 1886). This means that the forehand and hindquarters are displaced laterally in relation to each other, such that one diagonal pair of limbs are oriented to more in the intended direction of motion. However, each of the two exercises targets a different diagonal. This can be expected to result in movements asymmetries between forelimb and hind limb pairs, respectively, in the same way that moving on a curved track, e.g. a circle, creates asymmetries between inside and outside limbs. Such asymmetries were indeed found in the current study, though the interpretation requires some consideration, since these were overlaid on the asymmetries caused by moving on a circle. Important goals of lateral exercises are to increase weight carriage by the hindquarters, and to increase shoulder freedom (Hess et al., 2012; Steinbrecht, 1886). Our results suggest that these goals were reached to some degree for the respective targeted diagonals. The lateral exercises showed some of the same features as the collected exercises, but not to the same degree for both inner and outer limbs/steps. In shoulder-in, inner hind limb cannon ROM was smaller, and in haunches-in the outer hind had smaller ROM and decreased retraction, compared to neutral seat. In shoulderin, $\mathrm{ROM}$ and protraction were reduced for the inner fore but not for the outer fore, and in haunches-in, ROM and protraction were reduced for the outer fore but not for the inner fore. Decreased cannon ROM was observed with increasing collection in the current study and decreased hind limb retraction has been shown previously to be a feature of collection comparing working or collected trot to passage and piaffe (Holmström et al., 1995; Weishaupt et al., 2009). Similarly, metatarsal retraction decreased from extended to collected walk (Clayton, 1995). Collection is a prerequisite for the lateral exercises (Hess et al., 2012; Steinbrecht, 1886), and performing lateral exercises should also increase the horse's degree of collection (Hess et al., 2012). Looking at midline variables, lateral exercises showed additional similarities to the collected exercises: S1 ROM decreased during both inside and outside steps in both exercises, and withers ROM tended to increase. Taken together, these findings suggest that the lateral exercises were indeed collected and/or had a collecting effect on the targeted hind limb. The retained ROM and protraction of the diagonal forelimb, despite a shortening of the hind limb gait, may reflect what equestrians describe as increased shoulder freedom.

S1 ROM, withers ROM and cannon pitch ROM all reached their highest values in free walk after the other exercises. This suggests that there was a warming-up effect of going through the trial. The horses seem to have walked with a longer stride length after the other exercises compared to before, perhaps from being more relaxed and supple. Since the complete sequence of ridden exercises was performed in each direction, before changing, it is not clear to what extent this warming-up effect occurred after work in only one direction or if both directions were needed for full effect. The cumulative effect of different exercises would be an interesting topic for further research, but it was outside the scope of the current study to elucidate this further.

Comparing our results to previous studies that have measured cannon pitch using high-speed video, stride curve shapes and approximate ROM are in agreement (Clayton, 1995; Hodson et al., 2000, 2001). In horses ridden 
on treadmill in a collected posture (neck raised, poll high and bridge of the nose slightly in front of the vertical), forelimb protraction-retraction stride ROM was found to be $56^{\circ}$ and hind limb stride ROM $40^{\circ}$ (Rhodin et al., 2018), using the hoof and the elbow joint and fifth lumbar vertebra (L5), respectively, as reference points (also high-speed video data). For the most collected exercise, our least square means for cannon ROM were $57^{\circ}$ and $47-50^{\circ}$ for fore- and hind limbs, respectively. Compared to Rhodin et al. (2018), our figures are similar for the forelimbs and slightly larger for the hind limbs. Forelimb cannon maximum retraction occurs in-between forelimb lift-off and maximum flexion of the carpal joint (which occurs at $\sim 70 \%$ of the stride, (Hodson et al., 2000)), i.e. cannon retraction continues as the forelimb flexes during protraction. This implies that we should have found larger forelimb protraction-retraction ROMs compared to Rhodin et al. (2018), but this was not the case. Our mixed group of horses, predominantly of Iberian breed, may have contributed to differences between the two studies (Cano et al., 2001), but the differences may also reflect circle-induced effects.

Withers ROM varied between 12-18 mm and S1 ROM between 30-51 $\mathrm{mm}$. In a previous study on straight line walk mean ROM was considerably higher: $36 \mathrm{~mm}$ for the withers and $73 \mathrm{~mm}$ for L5 when horses were walking with a free head and neck position (Rhodin et al., 2018). One reason for the lower values in the current study could be that our horses were somewhat smaller. Another reason is that displacements derived from IMU sensors are the result of double integration from accelerations, rather than measured directly. Looking at our data graphically, the regular curve shape of S1 vertical motion can be contrasted to the more irregular withers trajectory (Figure 2 and Supplementary Figure S1). We have earlier demonstrated, using IMUdata from the same experiment, that when rider weight is added to the horse on the circle, the 'original/inherent' biphasic withers vertical motion pattern of the walk will often change to an irregular pattern with higher frequency components (Egenvall et al., 2020a). The reason for this is uncertain. A possible reason would be interference from the saddle, though that does not explain why the traces were comparably less irregular in free walk compared to in collection. Comparing the withers trajectory characteristics to high-speed video recordings of seven horses ridden and unridden in walk on a (straight) treadmill (Egenvall et al., 2020b), similarities can be seen between the current IMU data and high-speed video data from some of the horses. We are somewhat unsure to what extent the withers data we recorded reflect true withers motion. Considering findings in previous studies of straight-line walk, but at the same time also including a possible circle effect, it is difficult to tell. Interference from the saddle cannot be excluded, maybe in combination with the rider's weight and/or the horse's head-neck position, being influenced by the rider through the collecting exercises. However, withers motion per se also changes with a rider (Egenvall et al., 2020b). We have deemed that ROM values can be used, but at the same time we felt it was important to clearly express that the data quality could potentially be substantially worse than for other parameters.

The study material was collected from one trainer, whereas the group of horses and riders was fairly diverse. The latter can be considered both a limitation and a benefit, on one hand it introduces more random variation, on the other hand it supports the generalisation of significant findings to a larger population. The exercise program was constructed for this study (but emanated from training concepts used by the trainer, author HE, at the time). The goal of the study was that each horse and rider should achieve the best results possible there and then, if needed with verbal support from the trainer. Only the (subjectively) best performance achieved within the trial was used in the analysis to ensure that only high-quality data were analysed (in some trials some exercise sequences were deemed insufficient, resulting in missing data). The strict criteria for selecting exercise sequences resulted in that statistical power was lower for the lateral exercises and the highest degrees of collection, because there were fewer good strides available for these exercises. The timing variables were expressed as percentages of the cyclic gait motion, yielding data that were not optimally normally distributed. Thus, these parameters fitted the regressions less well, even if deemed to have an acceptable fit. The chaotic withers trace was problematic to analyse. In future research on collection and lateral exercises we suggest high-speed video capturing of midline markers placed on a larger number of anatomical positions to shed further light on the vertical forehand movement during riding. To include measurements on straight line in addition to circles would also be an asset.

The riders were given a questionnaire to determine the horses' hollow side, still from the answers sidedness was somewhat difficult to determine. The hollow side was added as a fixed factor to the ROM models (both cannons and midline variables, Supplementary Results S1) but no relevant significant effects were found. To address the questions of objective and subjective 'biomechanical' laterality during training, a large number of horses need to be evaluated and better methods for determining sidedness at training likely need to be developed (Byström et al., 2019). Further, it was outside the scope of the study to investigate effects of interactions between left-right asymmetries in horses and in riders.

\section{Conclusions}

This study is the first to describe collection and lateral exercises in ridden walk on the circle. Fore- and hind limb cannon protraction-retraction ROM and S1 vertical ROM decreased with increasing degree of collection, suggesting 
that the riders achieved a shortening of the gait. In shoulderin and haunches-in, the diagonal oriented in the direction of motion showed decreased hind limb cannon ROM while forelimb cannon ROM was maintained; this could be related to the equestrian goals of lateral exercises, increased shoulder freedom and collection of the targeted diagonal.

\section{Supplementary material}

Supplementary material can be found online at https://doi. org/10.3920/CEP210019.

Figure S1. Time-normalised stride data for the S1 vertical displacement data by exercise, in left (upper row) and right (lower row) directions on the circle for one horse.

Figure S2. Time-normalised stride data from one trial for left (inner) fore- and right (outer) hind (upper row) and right (outer) fore- and left (inner) hind (bottom row) cannon pitch angles in walk on the circle in left direction.

Table S1. Questions asked about horse laterality during riding, the last column containing the interpretation.

Table S2. Distribution of number of selected strides by exercise. $\mathrm{N}$ denotes number of trials with data in this exercise. Trials $(n=21)$ with only one stride each were deleted from the cannon pendulation analyses.

Results S1. Data, code and output used in the statistical analysis.

\section{Acknowledgements}

We would like to thank the riders. Funding for the experiment was provided by a Career Grant provided to author AE from the Swedish University of Agricultural Sciences.

\section{Conflict of interests}

None of the authors have any conflicting interests.

\section{References}

Branderup, B., 2001. Ridning på kandar: en praktisk handledning för ryttare, $1^{\text {st }}$ edition. Kapson hästböcker, Åkersberga, Sweden. [in Swedish]

Byström, A., Clayton, H.M., Hernlund, E., Rhodin, M. and Egenvall, A., 2019. Equestrian and biomechanical perspectives on laterality in the horse. Comparative Exercise Physiology 16: 35-45. https:// doi.org/10.3920/CEP190022

Cano, M.R., Vivo, J., Miro, F., Morales, J.L. and Galisteo, A.M., 2001. Kinematic characteristics of Andalusian, Arabian and Anglo-Arabian horses: a comparative study. Research in Veterinary Science 71: 147-153. https://doi.org/10.1053/rvsc.2001.0504
Chateau, H., Degueurce, C. and Denoix, J.-M., 2010. Three-dimensional kinematics of the equine distal forelimb: effects of a sharp turn at the walk. Equine Veterinary Journal 37: 12-18. https://doi. org/10.2746/04251640544069461

Clayton, H.M., 1995. Comparison of the stride kinematics of the collected, medium, and extended walks in horses. American Journal of Veterinary Research 56: 849-852.

De CocQ, P., Mooren, M., Dortmans, A., Van Weeren, P.R., Timmerman, M., Muller, M. and Van Leeuwen, J.L., 2010. Saddle and leg forces during lateral movements in dressage. Equine Veterinary Journal 42, Suppl. 38: 644-649. https://doi.org/10.1111/j.20423306.2010.00201.x

De la Guérinière, F.R., 1994, original 1729. School of horsemanship. Allen, London, UK.

Egenvall, A., Byström, A., Roepstorff, L., Rhodin, M., Weishaupt, M.A., Van Weeren, R. and Clayton, H.M., 2020b. Withers vertical movement asymmetry in dressage horses walking in different head-neck positions with and without riders. Journal of Veterinary Behavior 36: 72-83. https://doi.org/10.1016/j.jveb.2019.10.010

Egenvall, A., Engström, H. and Byström, A., 2020a. Kinematic effects of the circle with and without rider in walking horses. PeerJ 8: e10354. https://doi.org/10.7717/peerj.10354

Eisersiö, M., Roepstorff, L., Rhodin, M. and Egenvall, A., 2015. A snapshot of the training schedule for 8 professional riders riding dressage. Comparative Exercise Physiology 11: 35-46. https://doi. org/10.3920/CEP140024

Fédération Equestre Internationale (FEI), 2020. Dressage rules, $25^{\text {th }}$ edition. FEI, Lausanne, Switzerland. Available at: https://inside.fei. org/sites/default/files/FEI_Dressage_Rules_2020_Clean_Version.pdf

Hess, C., Kaspareit, T., Miesner, S., Plewa, M. and Putz, M., 2012. Grundausbildung für Reiter und Pferd. Richtlinien für Reiten und Fahren. Band 1. FN verlag, Warendorf, Germany.

Hobbs, S.J., Licka, T. and Polman, R., 2011. The difference in kinematics of horses walking, trotting and cantering on a flat and banked 10 m circle. Equine Veterinary Journal 43: 686-694. https://doi. org/10.1111/j.2042-3306.2010.00334.x

Hodson, E.F., Clayton, H.M. and Lanovaz, J.L., 2001. The hind limb in walking horses: 1 . Kinematics and ground reaction forces. Equine Veterinary Journal 33: 38-43. https://doi. org/10.2746/042516401776767485

Hodson, E.F., Clayton, H.M. and Lanovaz, J.L., 2000. The forelimb in walking horses: 1 . Kinematics and ground reaction forces. Equine Veterinary Journal 32: 287-294. https://doi. org/10.2746/042516400777032237

Holmström, M., Fredricson, I. and Drevemo, S., 1995. Biokinematic effects of collection on the trotting gaits in the elite dressage horse. Equine Veterinary Journal 27: 281-287. https://doi. org/10.1111/j.2042-3306.1995.tb03078.x

Newcastle, W.C., 2000, original 1658. A general system of horsemanship. Trafalgar Square Publication, London, UK.

Rhodin, M., Byström, A., Roepstorff, L., Hernlund, E., Van Weeren, P.R., Weishaupt, M.A. and Egenvall, A., 2018. Effect of different head and neck positions on kinematics of elite dressage horses ridden at walk on treadmill. Comparative Exercise Physiology 14: 69-78. https://doi.org/10.3920/CEP180002 


\section{A. Egenvall et al.}

Rhodin, M., Gomez Alvarez, C.B., Byström, A., Johnston, C., Van Weeren, P.R., Roepstorff, L., and Weishaupt, M.A., 2009. The effect of different head and neck positions on the caudal back and hind limb kinematics in the elite dressage horse at trot. Equine Veterinary Journal 41: 274-279. https://doi.org/10.2746/042516409x394436

Steinbrecht, G., 1886. The gymnasium of the horse, $1^{\text {st }}$ edition. Xenophon Press, Nassawadox, VA, USA.

Wakeling, J.M., Barnett, K., Price, S. and Nankervis, K., 2006. Effects of manipulative therapy on the longissimus dorsi in the equine back. Equine Comparative Exercise Physiology 3: 153-160. https://doi. org/10.1017/ECP200693
Weishaupt, M.A., Byström, A., Von Peinen, K., Wiestner, T., Meyers, H., Waldern, N., Johnston, C., Van Weeren, P.R. and Roepstorff, L., 2009. Kinetics and kinematics of the passage. Equine Veterinary Journal 41: 263-267. https://doi.org/10.2746/042516409x397226

Weishaupt, M.A., Wiestner, T., Von Peinen, K., Waldern, N., Roepstorff, L., Van Weeren, R., Meyer, H. and Johnston, C., 2006. Effect of head and neck position on vertical ground reaction forces and interlimb coordination in the dressage horse ridden at walk and trot on a treadmill. Equine Veterinary Journal, Suppl. 36: 387-392. https:// doi.org/10.1111/j.2042-3306.2006.tb05574.x

Xenophon, 2006, original 350 BC. The art of horsemanship. (translated from Ancient Greek). Dover, Mineola, NY, USA. 